\title{
A QUÍMICA DA VIDA COMO NÓS NÃO CONHECEMOS
}

\section{Pabulo Henrique Rampelotto}

Centro Interdisciplinar de Pesquisas em Biotecnologia, Universidade Federal do Pampa, CP 1847, 97300-000 São Gabriel - RS, Brasil

Recebido em 4/8/11; aceito em 2/3/12; publicado na web em 15/6/12

\begin{abstract}
THE CHEMISTRY OF LIFE AS WE DO NOT KNOW IT. It has been widely suggested that life based on carbon and water is the only plausible biochemistry, and specifically that terrestrial biochemistry of nucleic acids, proteins, and sugars is likely to be universal. However, according to our current knowledge of physics and chemistry, this may be just a geocentric concept. In recent decades, laboratory experiments and theoretical studies have indicated that life could be based on molecular structures substantially different from those we know. In this work, these studies are discussed in order to improve our knowledge on the fundamental nature of life.
\end{abstract}

Keywords: life; astrobiology; geocentric concept.

\section{INTRODUÇÃO}

Atualmente é consenso na comunidade científica que os primeiros seres vivos em nosso planeta são o resultado de uma longa evolução química, a qual precedeu a evolução biológica. Esta hipótese, inicialmente introduzida pelo bioquímico soviético A. I. Oparin, em 1924, e independentemente pelo biólogo britânico J. B. S. Haldane (em 1929, antes que o primeiro livro de Oparin fosse traduzido para o inglês), postula que a vida se originou na Terra depois de uma longa evolução de moléculas orgânicas simples até as mais complexas, incluindo macromoléculas de capacidade autorreplicativa.

O experimento clássico de Stanley Miller foi a primeira evidência experimental que a hipótese de Oparin-Haldane poderia estar correta. ${ }^{2}$ Nesse esperimento, Miller usou uma mistura dos gases metano $\left(\mathrm{CH}_{4}\right)$, amônia $\left(\mathrm{NH}_{3}\right)$ e hidrogênio $\left(\mathrm{H}_{2}\right)$ para simular a atmosfera primitiva e eletrodos para gerar faíscas que simulariam os raios e também seriam fonte de energia para as reações químicas. A análise química da solução aquosa, algumas semanas depois do experimento iniciado, detectou a existência dos aminoácidos glicina, -alanina, -alanina, ácido aspártico e -aminoácido-n-butírico. Assim, demonstrou em laboratório a formação de compostos orgânicos de interesse biológico em condições similares às da atmosfera terrestre primitiva. Hoje, o experimento de Miller não é mais considerado representativo para os processos químicos que ocorreram na Terra há bilhões de anos atrás, uma vez que seu modelo de atmosfera primitiva não se encaixa com o modelo atual. Novos estudos geoquímicos indicam que a atmosfera terrestre nunca foi redutora (isto é, formada por gases em suas formas mais reduzidas, como $\left.\mathrm{CH}_{4}, \mathrm{NH}_{3} \mathrm{e} \mathrm{H}_{2}\right)$, mas sim oxidante $\left(\mathrm{CO}_{2}, \mathrm{CO}, \mathrm{H}_{2}\right.$, $\mathrm{N}_{2}$ ) ou, na melhor das hipóteses, mais ou menos redutora, e neste tipo de atmosfera o rendimento de aminoácidos produzidos é muito baixo. ${ }^{3}$

Entretanto, com este experimento, Miller iniciou o desenvolvimento da pesquisa experimental sobre evolução química e as origens da vida. ${ }^{4}$ Assim, pode-se dizer que Miller é o fundador do que hoje se conhece como química prebiótica, o estudo das reações químicas que conduziram ou poderiam ter conduzido ao surgimento da vida em nosso planeta.

Com o desenvolvimento de poderosas técnicas de análise química e molecular (por exemplo, cromatografia gasosa, espectroscopia de massa, cromatografia líquida de alta eficiência e ressonância magnética nuclear) foi possível realizar estudos moleculares e quirais dos produtos das reações químicas. ${ }^{5}$ Consequentemente, houve um grande

*e-mail: pabulo@lacesm.ufsm.br avanço nas pesquisas relacionadas à química prebiótica. Graças a estes trabalhos, conhecemos em detalhes como muitas das moléculas-chave da vida podem ter sido criadas no mundo prebiótico.

Descobertas nas últimas décadas, entretanto, têm mostrado que os limites da vida na Terra estão longe de serem definidos. ${ }^{6}$ Para qualquer ambiente natural com condições extremas investigado, uma variedade de micro-organismos não apenas tolera, mas também requer estas condições para sobreviver. Micro-organismos são encontrados a $6,7 \mathrm{~km}$ de profundidade na crosta terrestre e a mais de $10 \mathrm{~km}$ de profundidade nos oceanos, submetidos a pressões de até $110 \mathrm{Mpa}$ (1086 atm) $;{ }^{7}$ são encontrados, também, de ambientes extremamente ácidos

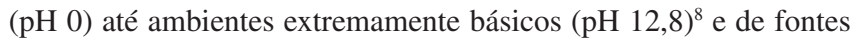
hidrotermais à temperatura de $122{ }^{\circ} \mathrm{C}$ até águas gélidas a $-20{ }^{\circ} \mathrm{C} .{ }^{9}$ Em adição às rotas metabólicas da fotossíntese, micro-organismos recentemente descobertos possuem metabolismo baseado em metano, enxofre e até mesmo ferro. ${ }^{6}$

Além disso, é importante salientar que, apesar dos recentes avanços, estamos apenas começando a explorar e a caracterizar o mundo dos extremófilos. A maior parte dos ambientes subterrâneos e suboceânicos ainda não foi estudada e apenas um pequeno número de micro-organismos já foram cultivados e descritos. ${ }^{10}$ Estima-se que mais de $90 \%$ da flora microbiana permaneça desconhecida. ${ }^{11}$ Por isso, novas descobertas no mundo microbiano podem ter um grande impacto em nosso conhecimento sobre a biosfera terrestre. Nesse contexto, a recente descoberta de Wolfe-Simon et al. ${ }^{12}$ tem o potencial de reavaliar nosso conhecimento de biologia. A autora e seus colaboradores publicaram a descoberta de uma nova bactéria que pode substituir arsênio (um elemento considerado altamente tóxico para os seres vivos) por fósforo em macromoléculas como ácidos nucleicos e proteínas. Por sua natureza controversa, este trabalho vem recebendo diversas críticas. As principais dizem respeito à alta instabilidade dos ésteres de arsênio em comparação aos ésteres de fosfato no DNA e à falta de evidências diretas de que o arsênio esteja sendo realmente incorporado ao DNA. ${ }^{13}$ Alguns pesquisadores sugerem que a bactéria em questão esteja simplesmente absorvendo e isolando o arsênio em vacúolos, enquanto faz uso do fósforo. ${ }^{14}$ Resultados mais claros serão possíveis quando for confirmada (ou não) a presença de arsênio no DNA ou RNA usando espectroscopia de massa. Se correta, esta descoberta irá ampliar nossa definição de vida como a conhecemos.

No laboratório, o advento de novas técnicas moleculares vem permitindo a construção de novas enzimas e outras macromoléculas. ${ }^{15}$ Um genoma viral já foi construído a partir de oligonucleotídeos. ${ }^{16} \mathrm{Em}$ 2010, foi anunciada a criação de uma célula bacteriana controlada 
por um genoma completamente artificial. ${ }^{17}$ Dessa forma, a emergente área científica da biologia sintética pode fornecer exemplos em laboratório de estruturas químicas alternativas capazes de suportar catálise e evolução darwiniana. ${ }^{18}$ Com estas técnicas revolucionárias temos o potencial de explorar se é possível construir vida com novas fisiologias, incluindo rotas metabólicas ainda não utilizadas pelos seres vivos.

Estes novos estudos e descobertas, que desafiam os paradigmas da biologia moderna, nos forçam a repensar questões tão intrigantes como "o que é vida?", "quais os seus limites?" e, principalmente, "quais são as suas características fundamentais?". Neste artigo, estas questões foram exploradas com o objetivo de ampliar o conhecimento sobre a natureza fundamental dos seres vivos, sendo eles conhecidos ou ainda a serem descobertos pela ciência. Na primeira parte, discutem-se as dificuldades de se definir vida e suas implicações na busca por vida extraterrestre. Na sequência, explora-se a possível química de formas alternativas de vida e onde estas hipóteses podem ser colocadas à prova em nosso sistema solar.

\section{O QUE É VIDA?}

Por séculos, teólogos, filósofos e cientistas vêm tentando encontrar uma resposta para essa questão. ${ }^{19}$ Há centenas de definições convencionais na literatura, mas nenhuma é capaz de atingir um consenso dentro da comunidade científica. Existem definições termodinâmicas, metabólicas, bioquímicas, genéticas e fisiológicas, para citar as mais comuns. ${ }^{20}$ Geralmente essas definições se resumem a meras listas de propriedades observáveis. Isso significa que embora a caracterização da vida seja possível, uma definição precisa do conceito de vida ainda está longe de ser estabelecida. Cada teoria, hipótese ou ponto de vista adota uma definição, de acordo com suas próprias premissas e interesse científico.

Atualmente, o conceito mais utilizado define vida como um "sistema químico autossustentável capaz de sofrer evolução darwiniana". ${ }^{21}$ Essa definição foi estabelecida em 1994 e desde então é adotada pela NASA. Entretanto, a capacidade de sofrer evolução darwiniana, um processo que resulta em mudanças herdáveis em uma população, não é suficiente para definir vida, se considerarmos que a capacidade de alguns minerais de reproduzir os erros em sua estrutura cristalina seja equivalente à evolução. Da mesma forma, o conceito de um sistema químico autossustentável pode ser aplicado com alguma justificativa para outros processos físico-químicos autossustentáveis, tais como os incêndios florestais.

De modo geral, as tradicionais definições de vida, que se resumem a meras listas de propriedades observáveis, falham em distinguir, de modo consistente, entre o mundo vivo e o não vivo. Logicamente, essa distinção entre os dois não é difícil de ser feita em nosso planeta (porém, mesmo para o nosso caso, alguns pesquisadores argumentam a existência de uma biosfera oculta, isto é, uma biosfera que não somos capazes de detectar simplesmente por ser diferente daquela com que estamos acostumados). ${ }^{22}$ Mas uma definição adequada torna-se relevante quando saímos do contexto familiar da Terra e encontramos condições mais exóticas e ambientes onde os fenômenos existem de modo completamente desconhecido para nós. Nesses casos, como reconhecer o que é vida e o que não é?

O único consenso que de fato existe entre os cientistas é que, apesar da grande biodiversidade, todos os seres vivos em nosso planeta derivam de um ancestral comum. Assim, pode ser prematuro tentar definir vida baseado em um único exemplo - a vida na Terra. Como pontuado por Cleland e Chyba, ${ }^{23}$ definições apenas nos dizem sobre o significado das palavras em nossa linguagem, ao invés de nos dizerem sobre a natureza do mundo. O que realmente precisamos é uma teoria geral dos seres vivos, análoga à teoria molecular que nos permite dar uma resposta sem ambiguidade para a questão "o que é água?". ${ }^{24}$ Antes da teoria molecular, o melhor que um cientista podia fazer para caracterizar água era defini-la em termo de suas propriedades sensíveis, tais como ser incolor, inodora e insípida. Quando se compreendeu a natureza molecular da matéria, foi possível identificar água de forma que toda a ambiguidade desapareceu: água é $\mathrm{H}_{2} \mathrm{O}$. Assim, uma resposta precisa para a questão "o que é água?" foi possível apenas quando situada dentro de uma teoria científica apropriada.

A falta de uma definição de vida, em alguns casos, pode ser problemática para as ciências biológicas. Isso fica evidente, por exemplo, na intensa discussão em relação aos vírus: são eles seres vivos ou não?; e mais recentemente pela surpreendente façanha da biologia sintética, como demonstrado pela síntese química de um genoma bacteriano completo e sua incorporação em um microplasma. ${ }^{17} \mathrm{Da}$ mesma forma, essa problemática se reflete nos debates gerados pelos avanços recentes na pesquisa biomédica que recaem sobre o aborto, a eutanásia e organismos transgênicos, para citar os mais comuns. Além disso, essa questão tem implicações profundas na procura por vida extraterrestre, como discutido na próxima seção.

\section{ASTROBIOLOGIA E A PROCURA POR VIDA EXTRATERRESTRE}

De modo geral, a astrobiologia é um ramo emergente da ciência que estuda a vida no universo. ${ }^{25}$ Esse amplo campo de pesquisas inclui o estudo da origem da vida na Terra e em outras partes do universo, bem como a procura por vida extraterrestre. ${ }^{26}$ Com esta afirmação, uma pergunta logo nos vem à mente: "o que exatamente estamos procurando?". Dessa forma, uma resposta adequada para a questão "o que é vida?" é fundamental para a astrobiologia, uma vez que o design dos experimentos de detecção de vida a ser realizado por telescópios e sondas espaciais depende de suposições sobre o que é vida e quais observações serão levadas em conta como prova para a sua detecção.

Até o momento, nós apenas conhecemos vida na Terra. Portanto, a procura por seres extraterrestres tem sido a procura por vida como nós conhecemos, baseada em um único exemplo. Acredita-se que exoplanetas capazes de sustentar vida orbitem dentro da chamada "zona habitável", a região ao redor de uma estrela na qual a água se encontra em estado líquido e onde a atmosfera pode conter dióxido de carbono, água e nitrogênio. ${ }^{27}$ Consequentemente, cientistas têm procurado por bioassinaturas produzidas por seres vivos extraterrestres em nosso sistema solar (isto é, em meteoros, planetas como Marte e Vênus e luas como Europa, Titã e Encélado) que se assemelham às células de organismos terrestres, moléculas derivadas do metabolismo celular, bem como aminoácidos e nucleotídeos similares a aqueles encontrados em proteínas e no DNA.

A vida provavelmente é o resultado de contingências físicas e químicas presentes no mundo onde ela surgiu. Em outros planetas, onde há ambientes similares aos da Terra, é muito provável que possa existir vida como nós conhecemos, isto é, que utiliza água como solvente e compostos carbônicos como blocos construtores. ${ }^{28}$ Entretanto, ainda não sabemos se realmente é lógico assumir esse pensamento geocêntrico. A Terra pode ser apenas um de muitos modelos de planetas que podem sustentar vida. Baseado em nosso limitado conhecimento sobre o assunto, não podemos simplesmente excluir a possibilidade de existir vida em ambientes muito diferentes da Terra, onde um conjunto de compostos químicos complexos, solventes e fontes de energia tornam-se possíveis a temperaturas, pressões e composições químicas diferentes das condições terrestres.

Desse modo, formas de vida que podem ter se originado em outro lugar, mesmo dentro de nosso próprio sistema solar, podem ser 
irreconhecíveis quando comparadas com a vida na Terra, não sendo possível detectá-las por telescópios e sondas espaciais destinadas a procurar biomoléculas terrestres ou seus produtos..$^{29}$ Devemos reconhecer que o nosso conhecimento sobre as características fundamentais da vida é baseado em nossa compreensão da biosfera durante as últimas fases da história da Terra. ${ }^{30}$ Uma vez que só conhecemos um exemplo de estruturas moleculares para a vida, é difícil imaginar como ela pode ser em ambientes muito diferentes dos que encontramos na Terra. Nas últimas décadas, entretanto, experimentos em laboratório e trabalhos teóricos vêm indicando que a vida pode ser baseada em estruturas moleculares substancialmente diferentes daquelas que conhecemos. A seguir, discutem-se algumas dessas possibilidades com base na literatura científica.

\section{POSSÍVEIS QUÍMICAS ALTERNATIVAS PARA A VIDA}

Embora ainda não haja uma definição precisa sobre a vida, é possível identificar três requisitos básicos para um ser vivo existir. ${ }^{31}$ Qualquer forma de vida requer a presença de uma grande quantidade e variedade de moléculas complexas para interagir com o meio externo e manter seu funcionamento interno. Da mesma forma, para manter sua alta complexidade química, a vida precisa de uma fonte externa de energia, e, finalmente, um meio líquido é necessário para manter a concentração e, ao mesmo tempo, o livre fluxo de compostos, permitindo rápidas interações moleculares. Baseados nesses três requisitos básicos e obedecendo aos princípios físicos e químicos existentes, discutimos, a seguir, como a vida pode existir de um modo ainda desconhecido para nós.

\section{Complexidade química}

Uma das características fundamentais da vida é sua complexidade química, baseada em moléculas poliméricas formadas por ligações covalentes. O carbono parece ser o único elemento capaz de formar polímeros que rapidamente sofrem alterações químicas sob as condições físicas prevalecentes na Terra. Devido a suas propriedades químicas, o elemento carbono pode formar um número quase ilimitado de moléculas, sendo que algumas delas são comuns no meio interestelar. ${ }^{32}$ Em consequência, espera-se que qualquer forma de vida que possa ser encontrada em outros planetas seja baseada no carbono. Entretanto, de acordo com nosso conhecimento atual da física e da química, esta pode ser apenas uma concepção geocêntrica.

Embora uma bioquímica baseada em polímeros de qualquer átomo diferente do carbono geralmente receba pouca atenção da comunidade científica, estudos recentes sugerem que um organismo pode ter um metabolismo completamente independente do carbono, isto é, um metabolismo cujo esqueleto principal das moléculas responsáveis pelas reações químicas seja formado por outros elementos além do carbono. ${ }^{33}$ Nesses estudos, o silício é o mais citado por estar diretamente abaixo do carbono na tabela periódica e, consequentemente, ser o elemento mais semelhante quimicamente. Algumas das semelhanças e diferenças entre silício e carbono que podem levar a alterações nas propriedades fisico-químicas e biológicas de moléculas são discutidas por Bains e Tacke, Showell e Mills. ${ }^{34}$ Como o carbono, o silício pode formar quatro ligações, ligações covalentes estáveis com ele mesmo e com outros elementos, além de formar compostos estáveis tetra, penta e hexacoordenados com N, C e O.$^{35}$ De fato, uma grande variedade de estruturas vêm sendo formadas de tal química (Figura 1). Além disso, a maior reatividade do silício comparada com a do carbono pode ser uma vantagem em ambientes extremamente frios, muito comuns no universo.

Logicamente, é importante ressaltar que, apesar de algumas características semelhantes, a química do Si é mais limitada que a do
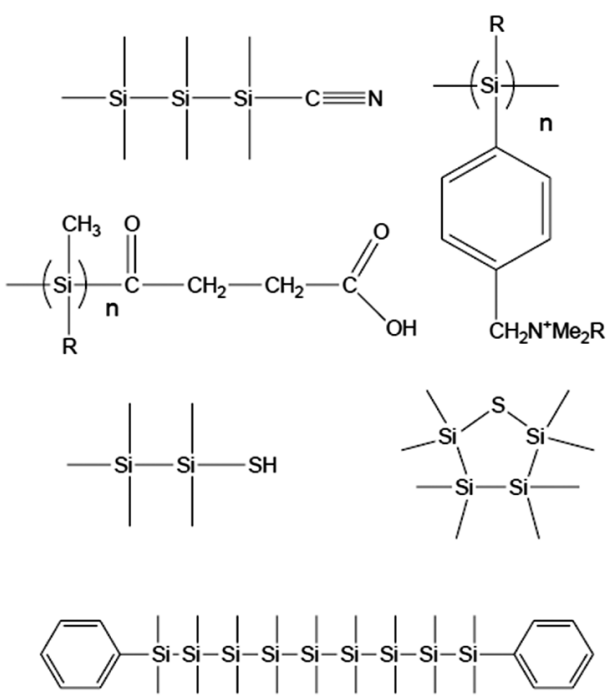

Figura 1. Estruturas de alguns polissilanos sintéticos descritos na literatura. Adaptada da ref. 57

carbono. Entretanto, as críticas em relação aos estudos com silício, geralmente, são baseadas na improbabilidade de vida baseada nesse elemento sob as condições ambientais terrestres. É evidente que a substituição direta de carbono por silício na bioquímica terrestre iria produzir moléculas que seriam quase que imediatamente hidrolisadas na água. Certos compostos derivados do silício, como silanos e muitos siloxanos, são espontaneamente inflamáveis a $0{ }^{\circ} \mathrm{C} .{ }^{36}$ Entretanto, estudos com silanos indicam que estes compostos poderiam se dissolver em nitrogênio líquido, ao invés de água, em concentrações suficientes para serem precursores da vida. ${ }^{37}$ É importante salientar que silanos são moléculas relativamente grandes, complexas e que podem levar à produção de polímeros complexos. ${ }^{38}$ Assim, sua flexibilidade estrutural e química em meio não aquoso pode gerar análogos funcionais à bioquímica terrestre.

Os elementos enxofre, nitrogênio e fósforo também são potenciais candidatos para formar o esqueleto principal de moléculas bioquímicas. ${ }^{39} \mathrm{O}$ enxofre é capaz de formar longas cadeias moleculares, como o carbono. Algumas bactérias terrestres foram descobertas em ambientes ricos em enxofre ao invés de oxigênio, reduzindo o enxofre a sulfeto de hidrogênio. ${ }^{40} \mathrm{O}$ fósforo é similar ao carbono em sua habilidade de formar longas cadeias moleculares, que podem levar à formação de macromoléculas complexas. Quando combinado com nitrogênio, pode-se criar uma grande variedade de moléculas, incluindo anéis.

Mesmo elementos altamente tóxicos para os seres vivos, como o arsênio, podem ser aproveitados por formas de vida sob as condições certas. Na Terra, algumas algas marinhas incorporam quantidades substanciais de arsênio em moléculas orgânicas complexas, como arseno-açúcares e arsenobetanoides. ${ }^{41}$ Recentemente, foi descoberta uma nova bactéria que pode substituir arsênio por fósforo em macromoléculas, como ácidos nucleicos e proteínas. ${ }^{14}$ Do mesmo modo, muitas outras formas de vida microscópica utilizam arsênio para gerar energia e facilitar seu crescimento.

\section{Fonte de energia}

Para manter sua alta complexidade química, a vida precisa de energia. Assim, uma fonte externa de energia é considerada fundamental para qualquer ser vivo. A energia proveniente do Sol é uma fonte quase ilimitada para a vida na Terra, sendo muito importante para o desenvolvimento da biosfera terrestre. Mesmo assim, há uma grande quantidade de seres vivos que sobrevivem usando outras fontes 
Tabela 1. Propriedades físicas dos solventes mais citados na literatura

\begin{tabular}{|c|c|c|c|c|c|c|c|c|c|c|c|}
\hline Solvente & $\begin{array}{l}\text { Fórmula } \\
\text { química }\end{array}$ & $\begin{array}{c}\text { Peso } \\
\text { molecular }\end{array}$ & $\begin{array}{l}\text { Densidade } \\
(\mathrm{g} / \mathrm{mL})\end{array}$ & $\begin{array}{l}\text { Ponto de } \\
\text { fusão } \\
\left({ }^{\circ} \mathrm{C}\right)\end{array}$ & $\begin{array}{c}\text { Ponto de } \\
\text { ebulição } \\
\left({ }^{\circ} \mathrm{C}\right)\end{array}$ & $\begin{array}{c}\text { Intervalo } \\
\text { líquido } \\
\left({ }^{\circ} \mathrm{C}\right)\end{array}$ & $\begin{array}{l}\text { Calor de } \\
\text { fusão } \\
(\mathrm{KJ} / \mathrm{mol})\end{array}$ & $\begin{array}{c}\text { Calor de } \\
\text { vaporização } \\
(\mathrm{KJ} / \mathrm{mol})\end{array}$ & $\begin{array}{c}\text { Constante } \\
\text { dielétrica } \\
(\varepsilon)\end{array}$ & $\begin{array}{l}\text { Viscosidade } \\
\quad\left(10^{-3} \mathrm{P}\right)\end{array}$ & $\begin{array}{c}\text { Momento } \\
\text { dipolo } \\
\text { (D) }\end{array}$ \\
\hline Água & $\mathrm{H}_{2} \mathrm{O}$ & 18,015 & 0,997 & 0 & 100 & 100 & 6 & 40,7 & 80,1 & 9,6 & 1,85 \\
\hline Amônia & $\mathrm{NH}_{3}$ & 17,031 & 0,696 & $-77,73$ & $-33,33$ & 44,4 & 5,7 & 23,3 & 16,6 & $2,7\left(-34^{\circ} \mathrm{C}\right)$ & 1,47 \\
\hline $\begin{array}{l}\text { Ácido } \\
\text { sulfúrico }\end{array}$ & $\mathrm{H}_{2} \mathrm{SO}_{4}$ & 98,08 & 1,831 & 10,7 & NA & 65,5 & 10,7 & NA & 101 & 260 & 2,7 \\
\hline Metano & $\mathrm{CH}_{4}$ & 16,04 & 0,426 & -182 & $-161,5$ & 20,5 & 0,94 & 8,2 & 1,7 & $0,009\left(20^{\circ} \mathrm{C}\right)$ & 0 \\
\hline Etano & $\mathrm{C}_{2} \mathrm{H}_{6}$ & 30,07 & 0,572 & -172 & -89 & 83 & 2,7 & 14,7 & 1,9 & $0,011\left(20^{\circ} \mathrm{C}\right)$ & 0 \\
\hline Nitrogênio & $\mathrm{N}_{2}$ & 28,01 & 0,85 & -210 & -196 & 14 & 0,71 & 5,56 & 1,45 & 2,04 & 0 \\
\hline Hidrazina & $\mathrm{N}_{2} \mathrm{H}_{4}$ & 32,05 & 1,004 & 1,6 & 113,5 & 111 & 12,7 & 40,9 & 51,7 & 9,8 & 1,9 \\
\hline $\begin{array}{l}\text { Cianeto de } \\
\text { hidrogênio }\end{array}$ & $\mathrm{HCN}$ & 27,02 & 0,684 & $-13,29$ & 26 & 39,3 & 8,4 & 25,2 & 114,9 & $2\left(20^{\circ} \mathrm{C}\right)$ & 2,99 \\
\hline $\begin{array}{l}\text { Sulfeto de } \\
\text { hidrogênio }\end{array}$ & $\mathrm{H}_{2} \mathrm{~S}$ & 34,02 & 1,393 & $-85,5$ & $-59,6$ & 25,9 & 2,4 & 18,7 & 5,9 & $4,3\left(61^{\circ} \mathrm{C}\right)$ & 0,98 \\
\hline Formamida & $\mathrm{CH}_{3} \mathrm{NO}$ & 45,04 & 1,13 & 3 & 211 & 208 & 8,44 & 60,1 & 110 & 33 & 33,4 \\
\hline Metanol & $\mathrm{CH}_{3} \mathrm{OH}$ & 32,04 & 0,793 & -94 & 65 & 159 & 2,2 & 40,5 & 354 & 5,9 & 1,6 \\
\hline
\end{tabular}

de energia. Esses organismos obtêm energia através de reações de oxidação-redução. Nesses casos, os metabolismos mais conhecidos envolvem reações com elementos químicos como hidrogênio, ferro e enxofre. ${ }^{42}$ Entretanto, muitas outras reações redox que geram energia para seres vivos são conhecidas e envolvem a oxidação e redução de elementos relativamente raros como o cobre, manganês, arsênio e selênio. ${ }^{43}$ Estes exemplos demonstram a capacidade da vida de usar diferentes formas de obter energia para sua sobrevivência. Deve-se lembrar que os seres vivos, de modo geral, são capazes de detectar calor, pressão e gravidade, bem como campos magnético e elétrico. ${ }^{44}$ Todos estes estímulos geram respostas pela transdução de sinais através da membrana celular, seja alterando a propagação dos íons que altera o potencial transmembrana, ou iniciando alterações metabólicas através de sistemas de mensageiro secundário. Isso indica como formas variadas de energia podem afetar processos biológicos. Neste sentido, estudos teóricos têm demonstrado que outras fontes de energia podem ser tão eficientes quanto as energias luminosa e química (reações redox) presentes na Terra para sustentar seres vivos sob um conjunto diferente de condições ambientais. ${ }^{45}$

Em nosso sistema solar várias fontes de energia, além de luz e reações redox, estão amplamente disponíveis e poderiam ser utilizadas por seres vivos. ${ }^{46}$ Energia geotérmica é indicada por vulcanismo, o que implica em aquecimento radiogênico em corpos planetários como Vênus e Marte. Pressão é uma fonte de energia em planetas com atmosfera espessa, como os gigantes gasosos e Vênus. Energia cinética é uma força presente em qualquer corpo planetário com forte convecção, como os gigantes gasosos e, possivelmente, Europa. A aceleração de marés é uma fonte de energia comumente encontrada no sistema solar, por exemplo em Io, Europa e Tritão. Fortes campos magnéticos e radiações emanadas de Júpiter e Saturno afetam seus satélites. Da mesma forma, pressão osmótica pode estar presente nas luas com suboceanos líquidos, tais como Europa, Ganimedes e Titã. ${ }^{46}$

Logicamente, isso não significa que tais fontes de energia sejam realmente usadas por seres hipotéticos, mas apenas que estão presentes e, portanto, preenchem um dos requisitos básicos para a emergência de vida em um corpo planetário.

\section{Meio líquido ou solvente}

A vida, como a conhecemos, consiste em interações químicas que ocorrem em um meio líquido, uma vez que as macromoléculas precisam ser fisicamente estáveis e, ao mesmo tempo, apresentar flexibilidade estrutural e reatividade química. Na Terra, o único líquido estável para os padrões físicos existentes é a água, que também é compatível com grande parte da química orgânica. Evidências recentes indicam que outros corpos planetários em nosso sistema solar podem abrigar água. ${ }^{47}$ Tais evidências levaram a NASA a adotar o princípio "siga a água" na procura por vida extraterrestre. Assim, a água, como o carbono, é considerada essencial para a vida.

Entretanto, novos estudos vêm demonstrando que vários outros solventes podem sustentar reações bioquímicas (Tabela 1). ${ }^{48}$ Dentre eles, a amônia é frequentemente o solvente mais citado. ${ }^{49} \mathrm{~A}$ amônia, como a água, dissolve diversos compostos orgânicos. Muitas reações orgânicas preparadas em laboratório são feitas com este solvente. Além disso, ela também é líquida em um amplo intervalo de temperatura (Figura 2).

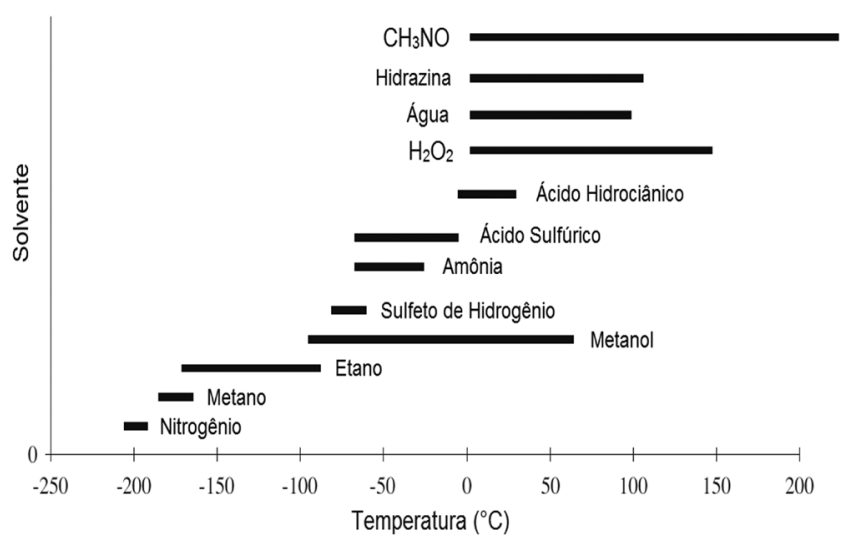

Figura 2. Intervalos de temperatura em que alguns solventes existem em estado líquido. Adaptada da ref. 51

As críticas em relação aos estudos com amônia ressaltam que a formação de micelas por compostos apolares neste solvente seria difícil. No entanto, a separação de fase hidrofóbica é possível em amônia em baixas temperaturas. Diferentes hidrocarbonetos tornam-se miscíveis com amônia em diferentes temperaturas e pressões. ${ }^{50}$ Assim, a formação de fases fóbica e fílica em amônia, análogas às fases hidrofóbica e hidrofílica em água, seria concebível em amônia, dependendo das condições de temperatura e pressão escolhidas. A 
agressividade da amônia como um nucleófilo implica que a bioquímica com base nesse solvente teria de ser diferente em comparação com a vida terrestre, como discutido adiante. Considerando que a amônia em sua forma líquida pode ser abundante no universo, ${ }^{51}$ sua potencial capacidade de sustentar vida alienígena é digna de consideração.

A amônia não é o único solvente polar que pode ser considerado uma alternativa à água. Ácido sulfúrico e formamida são solventes que suportam reatividade química. ${ }^{52}$ Além disso, não há necessidade de focar em solventes polares quando se considera possíveis habitats para a vida. Os hidrocarbonetos não polares, como metano e etano, são melhores do que água para a manutenção de reações químicas complexas, uma vez que não destroem hidroliticamente espécies orgânicas instáveis. ${ }^{49}$ Apesar de sua importância para a química da vida terrestre, na maioria das vezes, os químicos usam um solvente diferente da água para executar suas reações, pois ela própria é reativa, apresentando tanto um oxigênio nucleofílico quanto um hidrogênio ácido em concentrações de 55 molares.

É importante ressaltar que estudos experimentais envolvendo químicas alternativas para a vida são escassos e muitas das ideias discutidas nessa área ainda são especulativas. Com as recentes descobertas de possíveis mundos habitáveis em nosso sistema solar, este campo de pesquisa está começando a florescer. Na seção seguinte, apresentam-se algumas hipóteses de formas alternativas de vida que nosso conhecimento atual permite discutir.

\section{FORMAS ALTERNATIVAS DE VIDA EM NOSSO SISTEMA SOLAR}

Quando se discute sobre a procura por vida extraterrestre, uma das questões mais intrigantes que surge é "como tais formas exóticas de vida poderiam ser?" ou "quão semelhantes ou diferentes de nós elas seriam?"

A vida é provavelmente o resultado de contingências físicas e químicas presentes no mundo onde ela surge. Porém, mesmo as condições existentes na Terra primitiva não são claramente compreendidas, o que torna a origem da vida terrestre um problema longe de ser resolvido. ${ }^{53}$ Além disso, a história da vida na Terra mostra que a trajetória evolutiva de um ser vivo não pode ser prevista. As diversas formas inimagináveis que surgiram durante o período Cambriano são um bom exemplo da variedade de formas que a vida pode tomar. Desse modo, as particularidades de forma e função de uma história evolutiva de vida em outros mundos não podem ser conhecidas até serem encontradas. No entanto, apesar dessa potencial diversidade, em nível molecular, mecanismos básicos orientam o desenvolvimento de qualquer ser vivo. Assim, com base em princípios gerais de bioquímica é possível fazer previsões sobre a natureza de formas exóticas de vida que podem ser encontradas no universo. A seguir, discutimos algumas dessas possibilidades em nosso sistema solar, a única região do universo que podemos estudar detalhadamente nas próximas décadas.

\section{Vida à base de amônia}

A amônia, como revelado por suas propriedades físicas, pode ser um bom solvente para a vida (Figura 3) ${ }^{54} \mathrm{Na}$ verdade, macromoléculas, como proteínas, aminoácidos e ácidos nucleicos, contêm grupos funcionais $\mathrm{OH}$ e $\mathrm{NH}_{2}$ em várias combinações e proporções em que a amônia pode facilmente interagir. No entanto, uma bioquímica com base nesse solvente teria de ser diferente em comparação com a vida terrestre. Uma vez que o oxigênio oxida e dissocia as moléculas de amônia, a vida à base de amônia precisa de um ambiente sem a presença de oxigênio. ${ }^{55}$ Nesses ambientes, o metabolismo anaeróbico seria a alternativa. Análogos de biomoléculas terrestres, nos quais os átomos de oxigênio são substituídos por grupos $\mathrm{NH}$, podem produzir uma bioquímica igualmente viável (Figura 4). Reações de síntese, como a de proteínas, a partir de aminoácidos através de uma ligação peptídica mostram semelhanças em solução aquosa, amônica e misturas de água e amônia. ${ }^{56}$

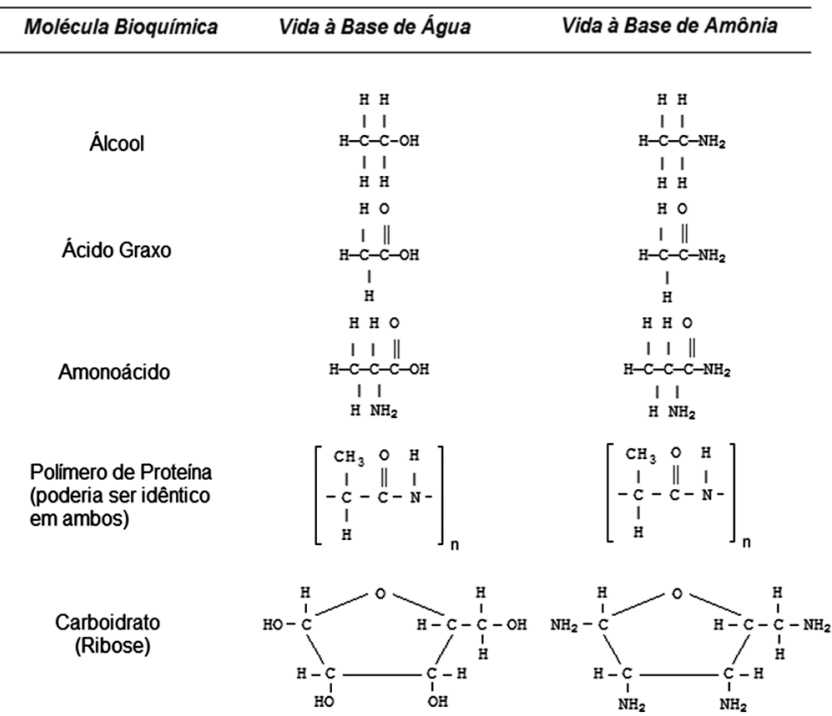

Figura 3. Comparação entre a bioquímica terrestre à base de água e uma possível bioquímica à base de amônia

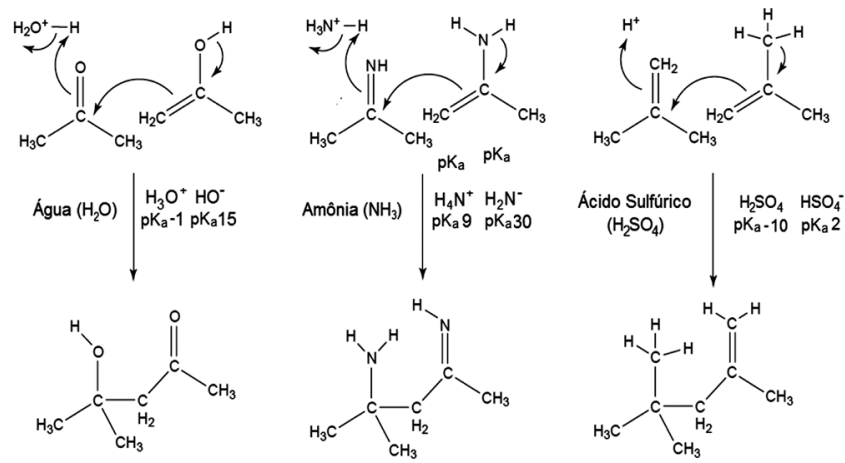

Figura 4. Diferentes grupos funcionais, mas mecanismos análogos, poderiam ser usados para formar ligações $C-C$ em diferentes solventes. Em água, a unidade $C=O$ forneceria a reatividade necessária. Em amônia, a unidade $C=N$ forneceria a reatividade necessária. Em ácido sulfúrico, a unidade $C=O$ é suficiente para fornecer a reatividade necessária. Adaptada da ref. 55

Diversas linhas de evidência sugerem que o oceano interno de Titã contém amônia, misturada com água, sob a forma de uma camada líquida abaixo de uma crosta de gelo. ${ }^{57}$ Além disso, o seu ambiente livre de oxigênio proporciona uma excelente oportunidade para encontrar seres vivos que utilizam amônia como solvente. A presença de $\mathrm{NH}_{3}$ no provável oceano interno de Encélado também tem chamado a atenção para a possibilidade de vida à base de amônia neste satélite. ${ }^{58}$

\section{Vida à base de metano}

As evidências recentes de lagos compostos de hidrocarbonetos na superfície de Titã, um dos satélites de Saturno, têm levado diversos cientistas a estudar a possibilidade de esses líquidos serem um solvente, no qual formas de vida podem se desenvolver. ${ }^{59}$ Estudos indicam que estes lagos são compostos de metano e etano, com traços de nitrogênio dissolvido. ${ }^{60} \mathrm{Um}$ ciclo de metano pode existir em Titã, semelhante ao ciclo hidrológico na Terra. ${ }^{61}$ Assim, esses 
reservatórios líquidos na superfície proporcionam um ambiente onde moléculas prebióticas, formadas na rica atmosfera de Titã, podem se acumular e diferenciar quimicamente. ${ }^{62}$ Considerando a quantidade e extensão dos lagos de metano e etano, se seres vivos florescem nesses ambientes líquidos e consomem compostos produzidos na atmosfera, espera-se que tais organismos tenham um efeito sobre o meio ambiente próximo à superfície.

Neste sentido, há alguns anos atrás, um estudo sugeriu um tipo de vida à base de metano em Titã. De acordo com os pesquisadores, micro-organismos poderiam reagir hidrogênio com material orgânico proveniente da atmosfera (como acetileno ou etano) para obter energia. $\mathrm{O}$ produto liberado, neste caso, seria metano. $\mathrm{O}$ estudo concluiu que os resultados da sonda Huygens poderiam indicar a presença de tais formas de vida pela diminuição anômala de acetileno e etano, bem como de hidrogênio na superfície de Titã. ${ }^{63}$ Pesquisas recentemente divulgadas parecem corroborar essa hipótese. Baseado em análises computacionais, um desses trabalhos prevê um intenso fluxo de hidrogênio da superfície para o interior de Titã. ${ }^{64}$ Outro estudo relatou uma diminuição de acetileno na superfície. ${ }^{65}$ Além disso, sabe-se que a concentração de etano na superfície de Titã é menor do que o esperado, enquanto metano é encontrado em abundância. ${ }^{66}$ Embora estes resultados não sejam provas de que realmente há vida em Titã, são relevantes. Ainda que a existência de vida em Titã seja um assunto em aberto, este satélite de Saturno é amplamente considerado ser um laboratório natural de química prebiótica em nosso sistema solar.

Em consequência destes resultados promissores, novos grupos de pesquisa vêm se formando ao redor do mundo com o objetivo de estudar em detalhes como seres vivos poderiam se desenvolver utilizando solventes como o metano. ${ }^{67}$

\section{Vida à base de ácido sulfúrico}

Nos últimos anos, o ácido sulfúrico tem sido sugerido como um possível solvente para a vida. Entre suas características, é liquido em um amplo limite de temperatura (de 10 a $337^{\circ} \mathrm{C}$ ), possui constante dielétrica e momento dipolo maiores que a água e apresenta alta viscosidade. ${ }^{49}$ Devido à sua capacidade de suporte à reatividade química, o ácido sulfúrico pode ser um solvente razoável, capaz de sustentar metabolismo em ambientes não aquosos (Figura 4).

A atmosfera de Vênus é o ambiente mais apropriado em nosso sistema solar onde essa forma exótica de vida pode florescer. As nuvens de Vênus são compostas principalmente de aerossóis de ácido sulfúrico e a presença de água é escassa. ${ }^{68} \mathrm{~A}$ camada de nuvens a $50 \mathrm{~km}$ acima da superfície poderia fornecer um ambiente propício à existência de vida, com pressões semelhantes às encontradas na Terra, e temperaturas de 20 a $80{ }^{\circ} \mathrm{C} .{ }^{69}$ Segundo hipóteses recentes, formas de vida poderiam ter se originado em um oceano primordial quando a superfície do planeta era mais jovem e fria: ${ }^{70}$ ao longo do tempo, quando o planeta começou um processo de aquecimento (atualmente, a temperatura na superfície de Vênus chega a $460{ }^{\circ} \mathrm{C}$ ) as formas de vida adaptadas a se desenvolver no ambiente atmosférico sobreviveram. ${ }^{71}$ Para proteger-se da grande quantidade de radiação UV recebida, estes seres vivos poderiam usar o composto ciclo-octa-enxofre (S8) que é encontrado em abundância na camada baixa da atmosfera venusiana e não reage com o ácido sulfúrico. Um processo semelhante é observado na Terra onde bactérias púrpuras sulfurosas, bactérias verdes sulfurosas e algumas espécies de cianobactérias depositam grânulos de enxofre na superfície externa da célula. ${ }^{72}$ Essas formas de vida venusiana poderiam ser fototróficas, usando sulfeto de hidrogênio $\left(\mathrm{H}_{2} \mathrm{~S}\right)$, o qual seria oxidado para produzir grânulos de enxofre elementar. ${ }^{73} \mathrm{Na}$ Terra, bactérias púrpuras sulfurosas utilizam esse processo anoxigênico como fonte de energia. ${ }^{74}$

\section{Vida à base de silício}

O silício pode formar longas cadeias de silanos, silicones e silicatos. ${ }^{75}$ Entre eles, os silanos foram considerados os compostos mais adequados para sustentar vida. ${ }^{33}$ Entretanto, uma forma de vida baseada em silício teria que ser completamente diferente da vida como conhecemos na Terra. Silanos entram em combustão espontaneamente em contato com oxigênio, formando silicato e hidrogênio molecular. Assim, uma bioquímica com base em tais compostos requer um ambiente livre de oxigênio. A afinidade do silício pelo oxigênio é tão forte que, se silício for colocado em um meio aquoso, vai formar um reservatório de sílica, retirando oxigênio da água. ${ }^{76}$ Dessa forma, a água não é um solvente compatível para os compostos de silício. Metano, etano, nitrogênio ou quaisquer compostos que contenham grupos metílicos são solventes mais compatíveis para um ser vivo à base de silício (Figura 5).

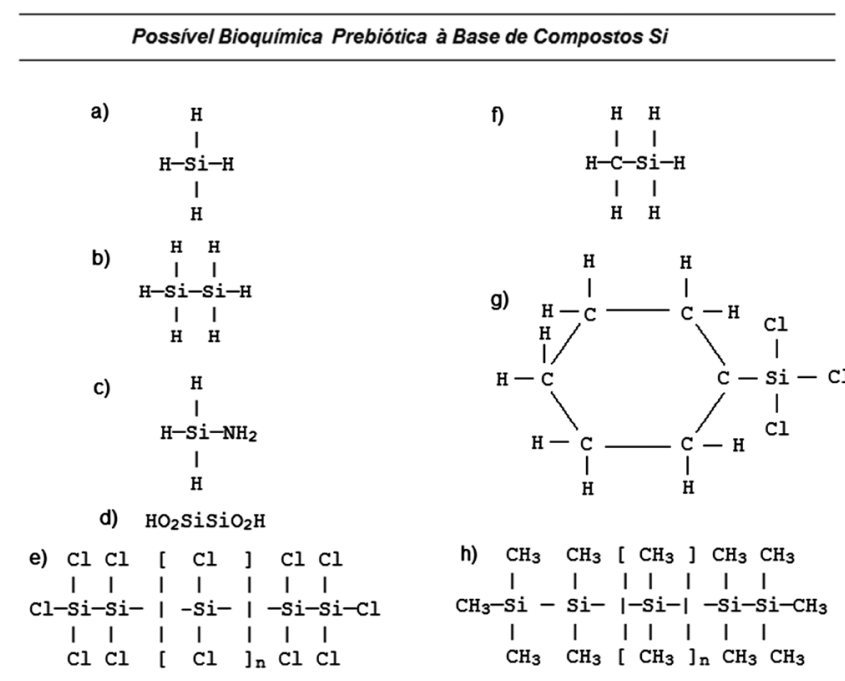

Figura 5. Possível química prebiótica à base de compostos de silício: a) Silano (análogo ao metano); b) Dissilano (análogo ao etano); c) Sililamina (análoga à metilamina. Muitas outras Si-aminas existem. As C-aminas são de grande importância na bioquímica terrestre); d) Oxiprossiloxano (análogo ao ácido oxálico); e) Percloropolissilano (demonstra que ligações Si-Si são estáveis até $n=21$ ); f) Metilsilicano (produzido usando $\mathrm{Si}$ em $\mathrm{H}_{2}, \mathrm{CH}_{4} \mathrm{em}$ experimentos semelhantes aos de Miller, com descargas elétricas e $\mathrm{BCl}_{3}$ ); $\mathrm{g}$ ) Ciclo-hexiltriclorossilano (produzido em experimentos semelhantes aos de Miller usando uma mistura de $\mathrm{SiCl}_{4}$ e $\mathrm{C}_{6} \mathrm{H}_{12}$ na ausência de água); h) Longas cadeias de polissilanos lineares permetilados

A forte ligação Si-O pode ser evitada, e reproduzido o cenário similar ao carbono, se oxigênio for substituído por enxofre. Além disso, polímeros de silício têm sido obtidos com nitrogênio em vez de oxigênio, onde o nitrogênio atua como um doador de elétrons. ${ }^{77}$ Nos ambientes pobres em hidrogênio, o mesmo é frequentemente substituído por um halogênio como cloro e são formadas longas cadeias lineares de silício e cloreto. ${ }^{78}$ As grandes moléculas com base no esqueleto $\mathrm{NH}-\mathrm{Si}$-Si, com halogênios como grupos laterais, poderiam fornecer a base para sistemas químicos complexos. Os silanos podem formar macromoléculas flexíveis com estrutura variada. ${ }^{79}$ Além disso, oligossilanos de até 26 ligações Si-Si consecutivas podem ser quirais, suportar uma variedade de cadeias laterais funcionais e não funcionais, tendo cadeias laterais alquila, que são geralmente solúveis em solventes apolares e autoagregados em estruturas anfifílicas na água, criando vesículas e micelas. ${ }^{80}$

Embora a estabilidade de silanos diminua com o aumento da cadeia, se hidrogênio for substituído por grupos orgânicos, são obtidos 
compostos estáveis. Por exemplo, polissilanos com pesos moleculares maiores que 100 já foram sintetizados. ${ }^{81}$ Embora polissilanos não sejam estáveis nas condições de temperatura e pressão da superfície da Terra, são suficientemente estáveis em baixas temperaturas, especialmente a altas pressões. Esses estudos sugerem que se a vida à base de silício existir pode ser limitada a ambientes com pequenas quantidades de oxigênio, escassez de água, um solvente compatível (como metano ou nitrogênio) e temperaturas extremamente baixas.

Titã é um excelente destino em nosso sistema solar para investigar essa possibilidade, pois satisfaz todos os critérios descritos acima. ${ }^{82}$ Embora se considere que a abundância de compostos carbônicos em Titã possa competir com os compostos de silício como blocos construtores da vida, o silício pode ser uma vantagem em ambientes extremamente frios, devido a sua alta reatividade.

Tritão, a maior lua de Netuno, é outra possibilidade onde vida à base de silício pode ser estudada. Este satélite é geologicamente ativo, apresentando atividade vulcânica, além de possuir uma tênue atmosfera e, em especial, um amplo reservatório de nitrogênio líquido fluindo abaixo da superfície, da mesma forma que lava flui abaixo da superfície terrestre. ${ }^{83}$ Estudos têm demonstrado que silanos podem se dissolver em nitrogênio líquido em concentrações suficientes para serem precursores de vida. Assim, Tritão possui os requisitos básicos para ser considerado um alvo em potencial para estudos astrobiológicos. ${ }^{84}$

\section{CONSIDERAÇÕES FINAIS}

Nosso amplo conhecimento da química terrestre nos leva a concentrar a atenção na química da água e do carbono, compostos em que a vida terrestre está baseada, e a química orgânica como conhecemos surgiu no século XIX, com base no isolamento de compostos da natureza. Esta tendência para retratar a vida levando-se em conta as características específicas da vida da Terra é a base para o que chamamos de princípio geocêntrico, como discutido por Rampelotto. ${ }^{29}$ Nossa tendência natural ao geocentrismo requer que se faça um grande esforço para ampliar a percepção sobre as características fundamentais da vida. Como só conhecemos um exemplo de vida, ainda não sabemos todas as suas potencialidades. Assim, não podemos descartar a possibilidade de que as características mais importantes da vida ainda não tenham sido descobertas. Características tradicionalmente apontadas como essenciais aos seres vivos podem ser apenas consequências de propriedades mais fundamentais, mas ainda desconhecidas. Neste sentido, os estudos aqui discutidos, explorando possibilidades alternativas de vida, são fundamentais para a formulação de uma teoria geral dos sistemas vivos que, por sua vez, pode nos guiar em direção a uma resposta para a questão "o que é vida?".

Além disso, princípios básicos da química nos advertem contra o pensamento geocêntrico em relação à vida. Através dos exemplos discutidos, é possível imaginar reações químicas que possam sustentar seres vivos envolvendo compostos não carbônicos, ocorrendo em outros solventes além da água ou que envolvam reações de oxidaçãoredução, sem oxigênio molecular. Esses estudos sugerem que, se seres vivos se originaram de forma independente em outros mundos que apresentam ambientes geoquímicos diferentes, eles provavelmente teriam selecionado diferentes solventes e biopolímeros para o metabolismo. Assim, em vez de procurar por bioassinaturas específicas que surgiram recentemente na história da Terra (como, por exemplo, oxigênio e ozônio), as futuras missões espaciais devem se concentrar na procura por vida baseada em suas características fundamentais, o que significa procurar pelas características da vida independente do material que a constitui. Ao assumir esta visão não geocêntrica, estaremos aumentando significativamente as chances de reconhecer um ser vivo, se nos deparamos com ele, em algum lugar do universo.

\section{REFERÊNCIAS}

1. Oparin, A. I.; The Origin of Life, Moscow Worker Publisher: Moscow, 1924 (em Russo); Haldane, J. B. S.; Rationalist Annual 1929, 3, 1.

2. Miller, S. L.; Science 1953, 117, 528.

3. Selsis, F. Em Astrobiology: Future Perspectives; Ehrenfreund, P.; Irvine, W. M.; Owen, T.; Becker, L.; Blank, J.; Brucato, J. R.; Colangeli, L.; Derenne, S.; Dutrey, A.; Despois, D.; Lazcano, A.; Robert, F., eds.; Kluwer Academic Publishers: New York, 2005; Heinrich, M. N.; Khare, B. N.; McKay, C. P.; Icarus 2007, 191, 765; Kasting, J. F. Em Prebiotic Evolution and Astrobiology; Wong, J. T. F.; Lascano, A., eds.; Landes Bioscience: Austin, 2009.

4. Zaia, D. A. M.; Quim. Nova 2003, 26, 260.

5. Wong, J. T. F.; Lascano, A.; Prebiotic Evolution and Astrobiology, Landes Bioscience: Austin, 2009; Rauchfuss, H.; Chemical Evolution and the Origin of Life, Springer-Verlag: Berlin, 2008.

6. Rampellotto, P. H.; Rosa, M. B.; Schuch, A. P.; Schuch, N. J.; Pinheiro, D. K.; Munakata, N.; Astrobiology 2007, 7, 528; Rampelotto, P. H.; Sustainability 2010, 2, 1602.

7. Pikuta, E. V.; Hoover, R. B.; Crit. Rev. Microbiol. 2007, 33, 183.

8. Rothschild, L. J.; Mancinelli, R. L.; Nature 2001, 409, 1092.

9. Cavicchioli, R.; Astrobiology 2002, 2, 281.

10. Rainey, F.; Oren, A.; Extremophiles, Academic Press: New York, 2006.

11. Epstein, S. S.; Uncultivated Microorganisms, Springer: New York, 2009

12. Wolfe-Simon, F.; Blum, J. S.; Kulp, T. R.; Gordon, G. W.; Hoeft, S. E.; Pett-Ridge, J.; Stolz, J. F.; Webb, S. M.; Weber, P. K.; Davies, P. C. W.; Anbar, A. D.; Oremland, R. S.; Science 2011, 32, 1163.

13. Schwartz, A. W.; Orig. Life Evol. Biosph. 2011, 41, 1.; Tawfik, D. S.; Viola, R. E.; Biochemistry 2011, 50, 1128.

14. Katsnelson, A.; Nature 2010, 468, 741.

15. Rothschild, L. J.; BioEssays 2010, 32, 304.

16. Smith, H. O.; Hutchison III, C. A.; Pfannkoch, C.; Venter, J. C.; Proc. Natl. Acad. Sci. U.S.A. 2003, 100, 15440.

17. Gibson, D. G.; Glass, J. I.; Lartigue, C.; Noskov, V. N.; Chuang, R. Y.; Algire, M. A.; Benders, G. A.; Montague, M. G.; Ma, L.; Moodie, M. M.; Merryman, C.; Vashee, S.; Krishnakumar, R.; Assad-Garcia, N.; Andrews-Pfannkoch, C.; Denisova, E. A.; Young, L.; Qi, Z. Q.; SegallShapiro, T. H.; Calvey, C. H.; Parmar, P. P.; Hutchison, C. A.; Smith, H. O.; Venter, J. C.; Science 2010, 329, 52.

18. Morange, M.; EMBO 2009, 10, 50.

19. Tsokolov, S. A.; Astrobiology 2009, 9, 401.

20. Pályi, G.; Zucchi, C.; Caglioti. L.; Fundamentals of Life, Elsevier: New York, 2002; Popa, R.; Between Necessity and Probability: Searching for the Definition and Origin of Life, Springer: Berlin, 2004.

21. Joyce, G. F. Em Origins of life: The Central Concepts; Deamer, D. W.; Fleischaker, G. R., eds.; Jones and Bartlett: Boston, 1994.

22. Cleland, C. E.; Stud. Hist. Phil. Biol. Biomed. Sci. 2007, 38, 847; Davies, P. C. W.; Phil. Trans. R. Soc. A 2011, 369, 624.

23. Cleland, C. E.; Chyba C. F.; Orig. Life Evol. Biosph. 2002, 32, 387.

24. Chyba, C. F.; Hand, K. P.; Annu. Rev. Astron. Astrophys. 2005, 43, 1

25. Plaxco, K. W.; Gross. M.; Astrobiology: A Brief Iintroduction, The Johns Hopkins University Press: Baltimore, 2006; Ehrenfreund, P.; Irvine, W. M.; Owen, T.; Becker, L.; Blank, J.; Brucato, J. R.; Colangeli, L.; Derenne, S.; Dutrey, A.; Despois, D.; Lazcano, A.; Robert, F.; Astrobiology: Future Perspectives, Kluwer Academic Publishers: New York, 2005.

26. Des Marais, D. J.; Nuth, J. A.; Allamandola, L. J.; Boss, A. P.; Farmer, J. D.; Hoehler, T. M.; Jakosky, B. M.; Meadows, V. S.; Pohorille, A.; Runnegar, B.; Spormann, A. M.; Astrobiology 2008, 8, 715; Bennett, J.; Beyound UFOs: The Search for Extraterrestrial Life, Princeton University Press: Princeton, 2008; Horneck, G.; Rettberg, P.; Complete Course in Astrobiology, Wiley-VCH: Darmstadt, 2007.

27. Rekola, R. T. F.; Planet. Space Sci. 2009, 57, 430; Fridlund, M.; Eiroa, C.; Henning, T.; Herbst, T.; Lammer, H.; Léger, A.; Liseau, R.; Paresce, 
F.; Penny, A.; Quirrenbach, A.; Röttgering, H.; Selsis, F.; White, G. J.; Absil, O.; Defrère, D.; Hanot, C.; Stam, D.; Schneider, J.; Tinetti, G.; Karlsson, A.; Gondoin, P.; den Hartog, R.; D’Arcio, L.; Stankov, A. M.; Kilter, M.; Erd, C.; Beichman, C.; Coulter, D.; Danchi, W.; Devirian, M.; Johnston, K. J.; Lawson, P.; Lay, O. P.; Lunine, J.; Kaltenegger, L.; Astrobiology 2010, 10, 5.

28. Brack, A.; Horneck, G.; Cockell, C. S.; Bérces, A.; Belisheva, N. K.; Eiroa, C.; Henning, T.; Herbst, T.; Kaltenegger, L.; Léger, A.; Liseau, R.; Lammer, H.; Selsis, F.; Beichman, C.; Danchi, W.; Fridlund, M.; Lunine, J.; Paresce, F.; Penny, A.; Quirrenbach, A.; Röttgering, H.; Schneider, J.; Stam, D.; Tinetti, G.; White, G. J.; Astrobiology 2010, 10, 69.

29. Rampelotto, P. H. Em Abiogenesis, Origins and the Search for Life; Russell, M., ed.; Cosmology Science Publishers: Cardiff, 2010.

30. Pilcher, C. B.; Astrobiology 2003, 3, 471.

31. Irwin, L. N.; Schulze-Makuch, D.; Astrobiology 2001, 1, 143.

32. Thaddeus, P.; Phil. Trans. Roy. Soc. B 2006, 361, 1681 .

33. Bains, W.; Astrobiology 2004, 4, 137; Baross, J. A.; Benner, S. A.; Cody, G. D.; Copley, S. D.; Pace, N. R.; Scott, J. H.; Shapiro, R.; Sogin, M. L.; Stein, J. L.; Summons, R.; Szostak, J. W.; The Limits of Organic Life in Planetary Systems, National Academic Press: Washington, 2007.

34. Bains, W.; Tacke, R.; Curr. Opin. Drug Discov. Devel. 2003, 6, 526; Showell, G. A.; Mills, J. S.; Drug Discov. Today 2003, 8, 551.

35. Brook, M. A.; Silicon in Organic, Organometallic and Polymer Chemistry, John Wiley: Toronto, 2000

36. Koda, S.; Prog. Energy Combust. Sci. 1992, 18, 513.

37. Murugavel, R.; Chandresekhar, V.; Voight, A.; Roesky, H. W.; Schmidt, H. G.; Noltemeyer, M.; Organometallics 1995, 14, 5298; Lickiss, P. Em The Chemistry of Organic Silicon Compounds; Rappoport, Z.; Apeloig, Y., eds.; John Wiley and Sons: New York, 2001.

38. Lickiss, P.; Adv. Inorg. Chem. 1995, 42, 174.

39. Ward, P.; Life as We Do Not Know It: The NASA Search for (and Synthesis of) Alien Life, Viking Adult: New York, 2005.

40. So, C. M.; Young, L. Y.; Appl. Environ. Microbiol. 1999, 65, 2969; Haouari, O.; Fardeau, M. L.; Casalot, L.; Tholozan, J. L.; Hamdi, M.; Ollivier, B.; Int. J. Syst. Evol. Microbiol. 2006, 56, 2909.

41. Barra, C. M.; Santelli, R. E.; de la Guardia, M.; Quim. Nova 2000, 23, 58.

42. Maier, R. M.; Pepper, I. L.; Gerba, C. P.; Environmental Microbiology, Academic Press: San Diego, 2000.

43. Madigan, M. T.; Martinko, J. M.; Stahl, D.; Clark, D. P.; Brock Biology of Microorganisms, $2^{\text {nd }}$ ed., Benjamin Cummings: San Francisco, 2010.

44. Blakemore, R. P.; Frankel, R. B.; Sci. Am. 1981, 245, 42; Braucker, R.; Cogoli, A.; Hemmersbach, R. Em Astrobiology: the Quests for the Conditions of Life; Horneck, G.; Baumstark-Khan, C., eds.; Springer: Berlin, 2002; Viswanath, V.; Story, G. M.; Peier, A. M.; Petrus, M. J.; Lee, V. M.; Hwang, S. W.; Patapoutian, A.; Jegla, T.; Nature 2003, 423, 822; Wilmer, P.; Stone, G.; Johnston, I.; Environmental Physiology of Animals, Blackwell: Oxford, 2000.

45. Muller, A. W. J.; Astrobiology 2003, 3, 555; Gusev, V. A.; SchulzeMakuch, D.; Naturwissenschaften 2005, 92, 115; Irwin, L. N.; SchulzeMakuch, D.; Cosmic Biology, Springer: New York, 2011.

46. Schulze-Makuch, D.; Irwin, L. N.; Life in the Universe: Expectations and Constraints, $2^{\text {nd }}$ ed., Springer: Berlin, 2008.

47. Encrenaz, T.; Annu. Rev. Astron. Astrophys. 2008, 46, 57.

48. Baross, J. A.; Benner, S. A.; Cody, G. D.; Copley, S. D.; Pace, N. R.; Scott, J. H.; Shapiro, R.; Sogin, M. L.; Stein, J. L.; Summons, R.; Szostak, J. W.; The Limits of Organic Life in Planetary Systems, National Academic Press: Washington, 2007.

49. Schulze-Makuch, D.; Irwin, L. N.; Naturwissenschaften 2006, 93, 155.

50. Brunner, E.; J. Chem. Thermodyn. 1988, 20, 1397; Barajas-Fernándeza, J.; Alvarado, J. F. J.; González-Alatorre, G.; Estrada-Baltazar, A.; González-García, R.; Fluid Phase Equilib. 2009, 279, 92.
51. Lewis, J. S.; Physics and Chemistry of the Solar System, $2^{\text {nd }}$ ed., Elsevier: London, 2004.

52. Naganuma, T.; Sekine, Y.; J. Cosmol. 2010, 5, 905.

53. Zaia, D. A. M.; Zaia, C. T. B. V.; Quim. Nova 2008, 31, 1599; Rampelotto, P. H.; J. Cosmol. 2009, 1, 86

54. Fortes, A. D.; Icarus 2000, 146, 444; Neish, C. D.; Somogyi, A.; Lunine, J. I.; Smith, M. A.; Icarus 2009, 201, 412.

55. Benner, S. A.; Ricardo, A.; Carrigan, M. A.; Curr. Opin. Chem. Biol. 2004, 8,672 .

56. Firsoff, V. A.; Life Beyond the Earth: A Study in Exobiology, Basic Books: New York, 1963; Raulin, F.; Bruston, P.; Paillous, P.; Sternberg, R.; Adv. Space Res. 1995, 15, 321.

57. Tobie, G.; Grasset, O.; Lunine, J. I.; Mocquet, J.; Sotin, C.; Icarus 2005, 175,496

58. Waite, Jr.; J. H.; Lewis, W. S.; Magee, B. A.; Lunine, J. I.; McKinnon, W. B.; Glein, C. R.; Mousis, O.; Young, D. T.; Brockwell, T.; Westlake, J.; Nguyen, M. J.; Teolis, B. D.; Niemann, H. B.; McNutt Jr.; R. L., Perry; M.; Ip, W. H.; Nature 2009, 460, 487.

59. Rampelotto, P. H. Em The Biological Big Bang: Panspermia and the Origins of Life; Wickramasinghe, C., ed.; Cosmology Science Publishers: Cardiff, 2010; Rampelotto, P. H.; $38^{\text {th }}$ COSPAR Scientific Assembly Abstracts Book, Bremen, Germany, 2010.

60. Stofan, E. R., Lunine, J. I.; Elachi, C.; Nature 2007, 445, 61; Lunine, J. I.; Lorenz, R. D.; Annu. Rev. Earth Planet. Sci. 2009, 37, 299.

61. Lunine, J. I.; Atreya, S. K.; Nature Geosci. 2008, 1, 160; Tokano, T.; McKay, C. P.; Neubauer, F. M.; Atreya, S. K.; Ferri, F.; Fulchignoni, M.; Niemann, H. B.; Nature 2006, 442, 432.

62. Raulin, F.; Nature 2008, 454, 587

63. McKay, C. P.; Smith, H. D.; Icarus 2005, 178, 274.

64. Strobel, D. F.; Icarus 2010, 208, 878.

65. Clark, R. N.; Curchin, J. M.; Barnes, J. W.; Jaumann, R.; Soderblom, L.; Cruikshank, D. P.; Brown, R. H.; Rodriguez, S.; Lunine, J.; Stephan, K.; Hoefen, T. M.; Le Mouélic, S.; Sotin, C.; Baines, K. H.; Buratti, B. J.; Nicholson, P. D.; J. Geophys. Res. 2010, 115, E10005.

66. Lorenz, R. D.; Mitchell, K. L.; Kirk, R. L.; Hayes, A. G.; Aharonson, O.; Zebker, H. A.; Paillou, P.; Radebaugh, J.; Lunine, J. I.; Janssen, M. A.; Wall, S. D.; Lopes, R. M.; Stiles, B.; Ostro, S.; Mitri, G.; Stofan, E. R.; Geophys. Res. Lett. 2008, 35, L02206.

67. Norman, L. H.; Fortes, A. D.; $A \& G$ 2011, 52, 39; Leitner, J. J.; SchulzeMakuch, D.; Firneis, M. G.; Hitzenberger, R.; Neubauer, D.; $10^{\text {th }}$ European Astrobiology Network Association Science Congress Abstracts Book, Pushchino, Russia, 2010.

68. Markiewicz, W. J.; Titov, D. V.; Limaye, S. S.; Keller, H. U.; Ignatiev, N.; Jaumann, R.; Thomas, N.; Michalik, H.; Moiss, R.; Russo, P.; Nature 2007, 450, 633

69. Svedhem, H.; Titov, D. V.; Taylor, F. W.; Witasse, O.; Nature 2007, 450, 629.

70. Schulze-Makuch, D.; Grinspoon, D. H.; Abbas, O.; Irwin, L. N.; Bullock, M.; Astrobiology 2004, 4, 11

71. Cockell, C. S.; Planet. Space Sci. 1999, 47, 1487.

72. Tortora, G.; Funke, B.; Case, C.; Microbiology: An Introduction, $5^{\text {th }}$ ed., Addison Wesley Longman: San Francisco, 2001.

73. Schulze-Makuch, D.; Irwin, L. N.; Astrobiology 2002, 2, 197.

74. Herbert, R. A.; Gall, A.; Maoka, T.; Cogdell, R. J.; Robert, B.; Takaichi, S.; Schwabe, S.; Photosynth. Res. 2008, 95, 261.

75. Jutzi, P.; Schubert, U.; Silicon Chemistry: From the Atom to Extended Systems, Wiley-VCH: New York, 2003.

76. Le Grand, A. P.; The Surface Properties of Silicas, John Wiley and Sons: New York, 1998

77. Murugavel, R.; Chandresekhar, V.; Voight, A.; Roesky, H. W.; Schmidt, H. G.; Noltemeyer, M.; Organometallics 1995, 14, 5298.

78. Tang, H.; Li, J.; Qin, J.; React. Funct. Polym. 2001, $48,193$.

79. Auner, N.; Weis, J.; Organosilicon Chemistry III: From Molecules to 
Materials, Wiley-VCH: Weinheim, 1998; Fan, H.; Chen, Z.; Brinker C. J.; Clawson, J.; Alam, T.; J. Am. Chem. Soc. 2005, 127, 13746; Muzafarov, A.; Silicon Polymers, Springer-Verlag: Berlin, 2011.

80. Sharma, H. K.; Pannell, K. H.; Chem. Rev. 1995, 95, 1351; Hengge, E.; Janoschek, R.; Chem. Rev. 1995, 95, 1495.

81. Rappoport, Z.; Apeloig, Y.; The Chemistry of Organic Silicon Compounds, John Wiley and Sons: New York, 2001.
82. Tokano, T.; Astrobiology 2009, 9, 147.

83. Ruiz, J.; Icarus 2003, 166, 436; Lellouch, E.; Bergh, C.; Sicardy, B.; Ferron, S.; Kauf, H. U.; Astron. Astrophys. 2010, 512, L8.

84. Rampelotto, P. H.; American Geophysical Union Abstracts Book, Foz do Iguaçu, Brasil, 2010; Irwin, L. N.; Schulze-Makuch, D.; Cosmic Biology, Springer: New York, 2011. 